\title{
USAGE OF INTERNET FOR HEALTH INFORMATION SEEKING AMONG ELDERLY IN MALAYSIA
}

\author{
Normawati Ahmad ${ }^{1}$ \\ ${ }^{1}$ Institute for Health Behavioural Research, \\ National Institute of Health, \\ Ministry of Health, \\ Malaysia \\ Noorlaile Jasman ${ }^{3}$ \\ ${ }^{3}$ Institute for Health Behavioural Research, \\ National Institute of Health, \\ Ministry of Health, \\ Malaysia
}
Siti Nur Farhana Harun ${ }^{5}$
${ }^{5}$ Institute for Health Behavioural Research, National Institute of Health,
Ministry of Health, Malaysia

\author{
Abu Bakar Rahman ${ }^{2}$ \\ ${ }^{2}$ Institute for Health Behavioural Research, \\ National Institute of Health, \\ Ministry of Health, \\ Malaysia \\ Kamarul zaman Salleh ${ }^{4}$ \\ ${ }^{4}$ Institute for Health Behavioural Research, \\ National Institute of Health, \\ Ministry of Health, \\ Malaysia \\ Manimaran Krishnan ${ }^{6}$ \\ ${ }^{6}$ Institute for Health Behavioural Research, \\ National Institute of Health, \\ Ministry of Health, \\ Malaysia
}

\author{
Mastura Johar ${ }^{7}$ \\ ${ }^{7}$ Universiti Tenaga Nasional, \\ Malaysia \\ Correspondence: Normawati Binti Ahmad, PhD.
}

Article DOI: https://doi.org/10.36713/epra4422

\begin{abstract}
Introduction: The Internet is rapidly growing and becoming an easier to access to technology. It functions as important part of almost everyone's daily life including elderly. Objective: The study was aimed to investigate the patterns of internet usage among elderly. Methods: A cross-sectional study was conducted in 23 Elderly Activity Centre throughout Malaysia from August 2017 to October 2017. This centre is a place for senior citizens to conduct routinely/daily activities in the community. It is an oriented service especially for senior citizens. Results: A total of 1400 individuals were sampled in this study, unfortunately the elderly turned up only 799 (57.1\%) which aged 60 and above. A self-administered with minimal guidance and face to face interview by trained research assistants were used in this study. The study showed of the total 799 respondents, only 258 (33.0\%) who use the internet. Those using the Internet are 89 (30.2\%) male and 169 $(69.8 \%)$ female, respectively. Most of them are government retirees (47.7\%). The study found that the reasons of the elderly seeking health information through the internet because it was free (66.3\%) as well as easy and fast (56.2\%). The study also found that the type of health information sought is information on certain diseases such as cancer, diabetes, hypertension and others (20.9\%). With regards to the places of internet access, about $86.8 \%$ of the respondents having the internet access at home, followed by internet service provider $42.6 \%$ and by Elderly Activity Centre, itself $14.7 \%$. Only $3.5 \%$ and $5.8 \%$ of respondents access internet at Cyber Cafe and friend's house respectively. The highest showed that respondents access internet several times in a month $25.5 \%$ followed by everyday $22.5 \%$ and twice or thrice in a week 17.4\%. Overall, $53.5 \%$ of elderly claimed internet can be a very helpful resource for finding health information. Discussion: Elderly in Malaysia are becoming more tech-savvy. This change is advantage as it can be used to address and manage health issues and geriatrics care for elderly through strategic dissemination of health information as well as to motivate positive health behaviour through use of technology.
\end{abstract}

KEYWORDS: Elderly, Internet Use, Health Information Seeking. 


\section{INTRODUCTION}

Elderly would be considered as a majority population of many countries. The growth of numbers of elderly is swiftly going higher than the whole number of the world population in every region around the world. The lowered of birth rate, the improvement of health care, better living condition also help lengthen people lives and simultaneously increasing numbers of Elderly (Loipha 2014). In Malaysia, numbers of elderly and the ratio have been increasing continuously. In 2017 , $6.2 \%$ of Malaysians representing the elderly $(>65$ years) from current population of 32.3 million and expected to hit $13.6 \%$ by 2030 (MHAS 2018).

Nowadays, the Internet is rapidly growing and becoming an easier to access to technology. It functions as important part of almost everyone's daily life including elderly. The Internet is used as an effective communication and it assists the boost of social collaborations, provides more channels of learning and interacting among people in the field of education, business and make things more possible to create new forms of activities (Hasim \& Salman 2010).

According to 2018 statistic, the usage of the Internet is constantly increasing $55.1 \%$ of the world population (Internet World Stats 2018), for Malaysia itself, there are now 32.3 million people or $78.3 \%$ of its population using the internet (Internet World Stats 2018). It is believed that there are many benefits of surfing the Internet; to fulfil elderly lives, to strengthened a better relationship among family's members and to narrow down the age gap relationship (Omsaung 2000). In addition, the Internet shows the changes of their world societies, energizes people and makes them feel younger and be trendier, and it adds more new friends into our daily life circles (Boonoon n.d).

Although the internet is believed to create better living conditions and is necessary of life-long learning tool that able to upgrade the elderly quality of lives in today's modern world, but in actual studies have shown looking for health information has been one of the most popular online activities among adults, and even among adolescents. But the online health information seeking behaviour of elderly has not been studied as closely as that of other age groups. In Malaysia, there are limited studies on Internet use among elderly. In accordance to a survey conducted by Malaysian Communications and Multimedia Commission (MCMC 2016) revealed that the groups of pre-teen and teens (up to 19 years old) and adults (20-49 years old) gained the highest portion of Internet use (81.5\%) as compared to those who were 50 years old or above with only $18.5 \%$ based on population. This huge gap between both generations is considered as "a digital divided problem"; therefore, to assist the elderly to be able to use the Internet as a part of their lives is becoming essential.

A study by the National Population and Family Development (2014) found that $10.4 \%$ of 4,059 senior citizens who participated in this study used Internet services with an average of two hours a day. Facilities of Internet service include social networks such as Facebook, WhatsApp, Twitter, and Instagram (68.2\%), e-mail (52.2\%), blogs and websites (45.6\%), and online banking (15.4\%).

A collaborative study between MCMC and Institute for Health Behavioural Research (IHBR), Ministry of Health Malaysia was conducted in 2017, regarding a study on seeking health information among Malaysians. The findings showed that $77.2 \%$ respondents searched for health information online. The most common health-related information that users were seeking were on 'symptoms and diseases' (91.4\%), followed by 'healthcare tips' $(89.8 \%)$, and 'treatment method' $(83.5 \%)$. Over half of them were looking for 'medications/drugs information' (73.3\%), as well as 'place to get treatment'. Furthermore, it was found that $82.7 \%$ trusted the health-related information found online regardless of the source. Only $5.7 \%$ felt otherwise, while the remaining $11.7 \%$ were neutral.

The internet is an important resource for health information (Dumitru et al. 2007). However, this does not tell us whether the Internet is used frequently or infrequently, why and how the Internet was used for gathering health information. It also does not address how the use of the Internet is compared to other sources of health information and whether the elderly would prefer to obtain health information from some other sources. This study was to identify health information seeking behaviour through Internet use among elderly. If we know about why and how elderly seek health information, we can more efficiently and effectively empower elderly by using the right information resource at the right time.

\section{METHODS}

A cross-sectional study was conducted in 23 Elderly Activity Centre throughout Malaysia from August 2017 to October 2017. Elderly activity centre is a place for seniors to conduct routinely/daily activities in the community. It is an oriented service especially for senior citizens. The development of the service involved collaboration between the Department of the Ministry of Women, Family and Community Development and other government agency and non-governmental organizations (NGOs).

Two-stage cluster sampling was used for this study. A total of 1400 individuals were sampled in this study; aged 60 years and above. Data were gathered using self-administered questionnaires as well as face to face interview. The questionnaires 
were adapted from previous studies (Maab 2011; Allen 2013; Loipha 2014). These questionnaires have been translated, pre-tested and validated accordingly to suit into the local settings and a pilot study has been embarked prior to the actual study. The questionnaire consists of two part, namely sociodemographics and questions to measure the use of internet in seeking health information among the elderly. The software program Statistical Package for the Social Sciences (SPSS) version 21.0 was used to perform statistical analysis. A descriptive analysis was used to illustrate the participation among elderly who use the internet.

\section{RESULTS}

\section{Demographic Characteristics of} Respondents

Table 1 presents the demographic data gathered from respondents. A total of 799 respondents from 23 PAWE localities were involved in this study with $69.8 \%$ females and $30.2 \%$ male. Majority of the respondents were Malays $45.0 \%$ and followed by Chinese $31.4 \%$. According to age groups, $36.5 \%$ were aged 60-64 years old while $31.2 \%$ were aged 65-69 years old. Furthermore, $46.0 \%$ have secondary education and $34.3 \%$ of them have primary education. In term of monthly income, $37.9 \%$ of the respondents had income less than RM1000. When viewed by occupational status, about $47.7 \%$ were retirees and $46.8 \%$ were unemployed. In term of marital status, most of the respondents were married (64.7\%) followed by divorced/widow/widower $(29.0 \%)$ and $5.6 \%$ were never married. A total of $65.3 \%$ of the 792 respondents reported that within the previous six months, their health has been good while another $34.7 \%$ felt that their health has been moderate.

\section{Table 1 Demographic of respondents $(\mathrm{N}=799)$}

\begin{tabular}{|c|c|c|}
\hline Characteristics & & Frequency, n (\%) \\
\hline \multicolumn{3}{|c|}{ Age groups (in years) } \\
\hline & $60-64$ & $292(36.5)$ \\
\hline & $65-69$ & $249(31.2)$ \\
\hline & $70-74$ & $134(16.8)$ \\
\hline & $75-79$ & $81(10.1)$ \\
\hline & $80-84$ & $33(4.1)$ \\
\hline & $85-89$ & $2(0.3)$ \\
\hline \multicolumn{3}{|l|}{ Gender } \\
\hline & Male & $241(30.2)$ \\
\hline & Female & $558(69.8)$ \\
\hline \multicolumn{3}{|l|}{ Ethnicity } \\
\hline & Malay & $360(45.0)$ \\
\hline & Chinese & $251(31.4)$ \\
\hline & Indian & $32(4.0)$ \\
\hline & Bumiputra Sabah & $52(6.5)$ \\
\hline & Bumiputra Sarawak & $102(20.3)$ \\
\hline & Others & $3(0.4)$ \\
\hline \multicolumn{3}{|l|}{ Educational level } \\
\hline & No formal education & $87(10.9)$ \\
\hline & Primary education & $274(34.3)$ \\
\hline & Secondary education & $367(46.0)$ \\
\hline & Tertiary education & $69(8.6)$ \\
\hline \multicolumn{3}{|l|}{ Monthly Income } \\
\hline & No income & $258(32.3)$ \\
\hline & Less than RM1000 & $303(37.9)$ \\
\hline & RM1001-RM3000 & $185(23.1)$ \\
\hline & RM3001-RM5000 & $34(4.3)$ \\
\hline & RM5001 and above & $8(1.0)$ \\
\hline \multicolumn{3}{|l|}{ Occupational Status } \\
\hline & Unemployed & $374(46.8)$ \\
\hline & Retired & $381(47.7)$ \\
\hline & Employed & $33(4.1)$ \\
\hline \multicolumn{3}{|l|}{ Marital Status } \\
\hline & Never married & $45(5.6)$ \\
\hline & Married & $517(64.7)$ \\
\hline
\end{tabular}


EPRA International Journal of Multidisciplinary Research (IJMR) - Peer Reviewed Journal Volume: 6 | Issue: 5 | May 2020 || Journal DOI: 10.36713/epra2013 || SJIF Impact Factor: 7.032 ||ISI Value: 1.188

\begin{tabular}{|c|c|c|}
\hline & Divorcee/Widow/Widower & $231(29.0)$ \\
\hline Health Status (n=792) & & $517(65.3)$ \\
\hline & Good & $275(34.7)$ \\
\hline & Moderate & 0 \\
\hline
\end{tabular}

\section{The Elderly Internet Usage behaviour}

As shown in Table 2, out of 799 respondents, only $258(32.3 \%)$ reported that they had used the internet. In relation to internet usage, it was found that most of the respondents have been using the Internet for more than 3 years $(67.1 \%), 18.6 \%$ have 1-3 years of experience and $10.6 \%$ have used it less than a year. Respondents were also asked tools for surfing, $86.4 \%$ indicated that they used smartphone to surf the internet.

Internet access was broadly defined to include use at home, elderly activity centre, workplace or any other location. Most elderly had accessed the internet $(86.8 \%)$ at their home. The frequency of the internet using time period: Most elderly access internet several times in a month (25.5\%), followed by everyday $(22.5 \%)$ and $2-3$ times in a week $(17.4 \%)$.

Table 2 The Elderly Usage Behaviour $(n=258)$

\begin{tabular}{|c|c|}
\hline The Elderly Usage Behaviour & Frequency, n (\%) \\
\hline \multicolumn{2}{|l|}{ Internet Usage } \\
\hline Yes & $258(32.3)$ \\
\hline No & $541(67.7)$ \\
\hline \multicolumn{2}{|l|}{ Duration of Internet Usage } \\
\hline Less than a year & $27(10.6)$ \\
\hline $1-3$ years & $48(18.6)$ \\
\hline More than 3 years & $173(67.1)$ \\
\hline \multicolumn{2}{|l|}{ Tools for surfing } \\
\hline Smartphone & $223(86.4)$ \\
\hline Tablet & $31(12.0)$ \\
\hline Computer Laptop & $83(32.2)$ \\
\hline Computer Desktop & $61(23.6)$ \\
\hline Others & $1(0.39)$ \\
\hline \multicolumn{2}{|l|}{ Internet Access } \\
\hline Home & $224(86.8)$ \\
\hline Elderly Activity Centre & $38(14.7)$ \\
\hline Restaurant/Food court & $31(12.0)$ \\
\hline Cyber Cafe & $9(3.5)$ \\
\hline Internet Service Provider & $110(42.6)$ \\
\hline Workplace & $14(5.4)$ \\
\hline Friends' House & $15(5.8)$ \\
\hline Other & $14(5.4)$ \\
\hline \multicolumn{2}{|l|}{ Frequency of Internet Usage } \\
\hline Everyday & $58(22.5)$ \\
\hline 2-3 times a week & $45(17.4)$ \\
\hline Once a week & $31(12.0)$ \\
\hline Once a month & $28(10.9)$ \\
\hline Several times in a month & $66(25.5)$ \\
\hline
\end{tabular}




\section{Experiences of using the Internet as a resource among Elderly \\ 3.1 Reasons for Using the Internet}

The main reason that most elderly liked about the Internet was that they could get an update on the current news $(88.4 \%)$ and seek for health information on the internet $(86.4 \%)$. Data also illustrated that $45.7 \%$ of respondents browsing the internet were mailing activities, followed by $41.1 \%$ respondents reported seek information about movies, music and television shows. Findings are described below and displayed in Table 3.

\subsection{Internet Health Seeking Purposes}

In regards to internet health seeking purposes, the study identified the top three reasons were personal health problem $67.8 \%$, followed by free information $66.3 \%$ and fast/convenient $56.2 \%$. Other common purpose of internet health seeking behaviour were because of various sources $47.7 \%$, others health problem $46.1 \%$, complete and accurate $43.0 \%$, privacy $24.4 \%$ and the least was $0.7 \%$ for other purposes.

(Table 3).

\subsection{Action Taken After Getting Health Information in the Internet}

Additional outcomes from the information found online were also sought. It was noted that $43.0 \%$ of respondents always preferred to discuss with their families, while $41.9 \%$ of respondents always seek treatment from a doctor. On the other hand, $36.4 \%$ of respondents always triggered by their curiosity to find out on the causes and treatments of health information problem (Table 3).

Table 3 Experiences of using the Internet as a resource among Elderly

\begin{tabular}{|l|c|}
\hline Experiences & Frequency, n (\%) \\
\hline Reasons for using the Internet & \\
\hline Health Information & $223(86.4)$ \\
\hline Current News & $228(88.4)$ \\
\hline Mailing & $118(45.7)$ \\
\hline Sale \& Purchase Transaction. & $66(25.6)$ \\
\hline Sport News & $74(28.7)$ \\
\hline Film/Music/TV Shows & $106(41.1)$ \\
\hline Stock Exchange Info & $24(9.3)$ \\
\hline Online Games & $35(13.6)$ \\
\hline Song Downloads & $42(16.6)$ \\
\hline & \\
\hline Internet Health Seeking Purposes & \\
\hline Free Information & $171(66.3)$ \\
\hline Personal Health Problem & $175(67.8)$ \\
\hline Others Health Problem & $119(46.1)$ \\
\hline Fast/Convenient & $145(56.2)$ \\
\hline Complete \& Accurate & $111(43.0)$ \\
\hline Privacy & $63(24.4)$ \\
\hline Various Sources & $123(47.7)$ \\
\hline Other purposes & $2(0.7)$ \\
\hline
\end{tabular}

\begin{tabular}{|l|c|}
\hline Action Taken After Getting Health Information in The Internet & Frequency, n (\%) \\
\hline Discuss with friends & $81(31.4)$ \\
\hline Discuss with family & $111(43.0)$ \\
\hline Discuss with doctor & $54(20.9)$ \\
\hline Curiosity & $94(36.4)$ \\
\hline Comply with appointment & $95(36.8)$ \\
\hline No treatment needed & $19(7.4)$ \\
\hline Get doctor treatment & $108(41.9)$ \\
\hline Get traditional treatment & $22(8.5)$ \\
\hline
\end{tabular}




\section{Type of Health Information Seeking}

As shown in Table 4, 39.9\% of the respondents seeking for violence information compared to others when seeking health information in the internet. Meanwhile, the respondents less search for sexual harassment $4.3 \%$ (Table 4 ).

Table 4 Type of health of information seeking

\begin{tabular}{|l|c|}
\hline \multicolumn{1}{|c|}{ Type of Health Information } & Frequency, n (\%) \\
\hline Dementia & $19(7.4)$ \\
\hline HIV/AIDS (STD) & $21(8.1)$ \\
\hline Pregnancy/Birth & $10(3.9)$ \\
\hline Drug/ Alcohol & $10(3.0)$ \\
\hline Smoking & $13(5.0)$ \\
\hline Depression/Mental Illness Eating Problem & $23(8.9)$ \\
\hline Skin Care & $80(31.0)$ \\
\hline Health Clinic & $45(17.4)$ \\
\hline Weight Problem & $37(14.3)$ \\
\hline Disease Information & $54(20.9)$ \\
\hline Violence & $103(39.9)$ \\
\hline Sexual Harassment & $11(4.3)$ \\
\hline Eyesight Problem & $15(5.8)$ \\
\hline Hearing Problem & $53(20.5)$ \\
\hline Others & $38(14.7)$ \\
\hline
\end{tabular}

\section{Barriers of Using Internet}

Outcomes from the study illustrated barriers of using Internet: Most elderly claimed that too much information difficulty for them to find information that they want (39.1\%). They also claimed that using internet can caused a risk of getting wrong advice $36.0 \%$, and unnecessary information and elusive information (both aspects were equal 25.9\%) (Table $5)$.

Table 5 Barriers of using Internet

\begin{tabular}{|l|c|}
\hline \multicolumn{1}{|c|}{ Barriers of Using Internet } & Frequency, $\mathbf{n}(\%)$ \\
\hline Information not relevance & $41(15.9)$ \\
\hline IT illiteracy & $69(26.7)$ \\
\hline Too much information & $101(39.1)$ \\
\hline Risk of getting wrong advice & $93(36.0)$ \\
\hline Information leak & $46(17.8)$ \\
\hline Risk of discussion & $38(14.7)$ \\
\hline Unnecessary information & $67(25.9)$ \\
\hline Refuse to see a doctor & $34(13.2)$ \\
\hline Elusive Information & $67(25.9)$ \\
\hline Internet bills burden & $54(20.9)$ \\
\hline Others & $5(1.9)$ \\
\hline
\end{tabular}

\section{Health Portal Ever Surfed}

The most top three health portal been surfed by respondent were MOH Portal $34.5 \%$, Nutrition Division Portal $27.5 \%$ and MyHEALTH Portal $19.4 \%$ (Table 6). 
Table 6 Health portal ever surfed

\begin{tabular}{|l|c|}
\hline \multicolumn{1}{|c|}{ Health Portal Ever Surfed } & Frequency, n (\%) \\
\hline Ministry of Health Portal & $89(34.5)$ \\
\hline Pharmacy Portal & $39(15.1)$ \\
\hline Health Education Division Website & $46(17.8)$ \\
\hline MyHEALTH Portal & $50(19.4)$ \\
\hline 'Tak Nak Merokok' Portal & $14(5.4)$ \\
\hline Pharmacy Services Portal & $24(9.3)$ \\
\hline Nutrition Division Portal & $71(27.5)$ \\
\hline Traditional \& Complimentary Medicine Portal & $32(12.4)$ \\
\hline Others & $22(8.5)$ \\
\hline
\end{tabular}

\section{The Usefulness Internet Health Information} Specifically, $53.5 \%$ respondents who reported using the internet stated that the health information that they found online was very useful, only $3.5 \%$ answered it as less useful and $0.8 \%$ as not useful at all (Table 7).

Table 7 The Usefulness Internet Health Information

\begin{tabular}{|l|c|}
\hline \multicolumn{1}{|c|}{ The usefulness Internet health information } & Frequency, $\mathbf{n}(\%)$ \\
\hline Very Useful & $138(53.5)$ \\
\hline Useful & $96(37.2)$ \\
\hline Less Useful & $9(3.5)$ \\
\hline Not at all useful & $2(0.8)$ \\
\hline
\end{tabular}

\section{DISCUSSION}

Internet use is no longer limited to younger people. Over the past years, elderly people have started using the Internet as older persons represent a large group of users that has steadily grown since 2000 (Pierce, 2009). In this study, it is revealed that nine out of ten of the elderly use the Internet to get an update on the current news as compared to seeking for health information online. The reason is because people are inclined to want to know the current issues occurring worldwide; however, health becomes a priority when it is needed.

The study also enquired about the factors that the elderly takes into consideration when looking health information online. A majority of the elderly look for disease information and eating problems as compared to others when seeking health information in the Internet. Given that most of the elderly suffer from a variety of illnesses, that is why finding information related to the disease is a priority and this is followed by nutrition.

The top three reasons why the elderly use online health information is to gain personal health problems, free information, and fast/convenient. This finding is consistent with previous studies whereby the Internet offers suitable, various, and cheap information as noted by Horgan and Sweeney (2010). While online health information has been influential for some elderly people, many others said they found it very useful to them.

The Internet can offer vast information; unfortunately, there are barriers to access the Internet such as too much information to choose from, risk of getting wrong advice, and unsure on how to find the information, thus making them trust and rely on the health staff to obtain health information. These may be the reasons why they do not turn to the Internet more often. This shows that the health staff members play a vital role in disseminating health information.

This study concludes that the Internet is assuming a more important role in the lives of the elderly and that its use is not only limited to current news and leisure purposes, but also used for lifesupporting and sustaining purposes including searching for health information.

\section{CONCLUSION}

Increase of internet-based dependency, use and literacy can be concluded for elderly in Malaysia as they are becoming more tech-savvy. This change is an advantage as it can be used to address and manage health issues and geriatric care for elderly through strategic dissemination of health information as well as to motivate positive health behaviour through use of technology. Although the findings of this survey should be considered preliminary, elderly who seek health information seem likely to use the Internet. Internet can be useful platform for ageing population as it caters health information. Future research should investigate how to reach seniors who prefer not to use the Internet for health information.

\section{Acknowledgement}

We would like to express our gratitude to the Director General of Health, Deputy Director General of Health (Research \& Technical Support) and 
National Institute of Health, Ministry of Health Malaysia (MOH) for their continuous support, granting the authorization for this publication and funding for the research. Special thanks to the Director of Institute for Health Behavioural Research (IHBR) for their support, guidance and advice throughout the process of the study. We would like to record our appreciation to the 23 Elderly Activity Centre throughout the country and Department of Social Welfare, Ministry of Women, Family and Community Development, Putrajaya for their commitments. We would also like to express appreciation for all the support from all parties that have contributed directly or directly to complete this study.

\section{Conflict of interest}

None

\section{Ethics of Study}

Ethical approval was obtained from Medical Research \& Ethical Committee, Ministry of Health, Malaysia with NMRR ID (16-2726-32123).

\section{Funds}

This study was funded by Ministry of Health Malaysia.

\section{REFERENCES}

1. Allen, S. (2013). Development and Validation of A Survey Instrument to Assess Health Information Seeking Behaviors Among African American Young Professionals [Dissertation]. Alabama: University of Alabama.

2. Boonnoon, J. (n.d.). Internet keeps senior citizen fresh. The Nation. Retrieved April 16, 2018 from http://www.happyoppy.com/index.php?lay=show $\& a c=$ article $\& I d=478697 \&$ Ntype $=14$

3. Department of Statistic, Malaysia. (2015). Investigation of the Use and Access of ICT by Individuals and Households.

4. Dumitru R.C., Burkle, T., Potapov, S., Lausen, B., Wiese, B. \& Prokosch, H.U. (2007). Use and

5. perception on Internet for health related purposes in Germany: results of a national survey. Int J Public Health 52(5):275-285.

6. Hasim, Mohd Safar, \& Salman, Ali. (2010). Factors affecting sustainability of internet

7. usage among youth. The Electronic Library. 28, 300-313.

8. Horgan, A.\& Sweeney, J. (2010). Young students' use of the internet for mental health information and support. Journal of Psychiatric and Mental Health Nursing, 17(2), 117-123.

9. Internet World Stats. (2018). Retrieved April 30, 2018 from

http://www.internetworldstats.com/stats.htm

10. Loipha, S. (2014). Thai Elderly Behavior of Internet Use. Procedia - Social and

Behavioral Sciences, 147, 104-10.
11. Maab. W. (2011). The Elderly and the Internet: How Senior Citizens Deal with Online Privacy | Request PDF. Retrived February 22, 2018, from https://www.researchgate.net/publication/291594 493_The_Elderly_and_the_Internet_How_Senior _Citizens_Deal_with_Online_Privacy.

12. Malaysian Communications and Multimedia Commission. (2016). Internet Users Survey.

13. Malaysian Communications and Multimedia Commission. (2017). Internet Users Survey.

14. Malaysian Healthy Ageing Society (MHAS). (2018).

15. Miller S. (1989). Cognitive informational styles in the process of coping with threat and frustration. Adv Behav Res Ther. 11, 223-34.

16. Mills, A., \& Todorova, N. (2016). An integrated perspective on factors influencing online healthinformation seeking behaviours. Australian Conference on Information Systems, 4: 6.

17. Omsaung. (2000). Internet without age. Retrieved April 16, 2018 from

http://www.happyoppy.com/index.php?la.

18. Pierce, J. (2009). Annual internet survey by the center for digital future finds large increases in use of online newspapers. Center for the Digital Future.

19. http://www.digitalcenter.org/pdf/2009_Digital_F uture Project Release Highlights.pdf. Accessed 25 Oct 2018

20. Peck, J.L. (2014). Social media in nursing education: responsible integration for meaningful use. J Nurs Educ, 19,1-6.

21. Report: 5th Malaysian Population and Family Study. 2014.

22. Von Muhlen, M., \& Ohno-Machado, L. (2012). Reviewing social media use by clinicians. $J$ Am Med Inform Assoc, 19(5),777-781. 